Vol.3 No.2 Hal. 120-125

September 2020

\title{
Studi Pengetahuan Masyarakat Terhadap Konsep Ekowisata Hutan Bakau Di Gampong Kuala Langsa
}

\author{
Siska Rita Mahyuni ${ }^{(1)}$, Ekariana S. Pandia ${ }^{(2)}$ \\ Pendidikan Bahasa Biologi dan Pendidikan Fisika \\ Fakultas Keguruan Dan Ilmu Pendidikan \\ Universtias Samudra \\ mahyunika@unsam.ac.id ${ }^{(1)}$, ekariana@unsam.ac.id ${ }^{(2)}$
}

\begin{abstract}
ABSTRAK
Penelitian ini bertujuan untuk mengetahui bagai mana tingkat pengetahuan masyarakat Kuala Langsa terhadap konsep ekowisata hutan mangrove yang berlokasi di area tersebut. Penelitian ini menggunakan metode deskriptif. Pengumpulan data dilakukan dengan cara angket dan wawancara. Hasil yang diperoleh dari penelitian ini bahwa hampir sebagian besar masyarakat sekitar kurang memahami konsep ekowisata di daerah Kuala Langsa. Hal tersebut dipengaruhi oleh beberapa faktor, seperti: rendahnya tingkat pendidikan mayoritas masyarakat (tamat SD) di Kuala Langsa, kurangnya intensitas edukasi ekowisata oleh pihak terkait, dan taraf ekonomi yang rendah sehingga masyarakat kurang memperhatikan isu lingkungan yang terjadi di wilayah ekowisata Kuala Langsa.
\end{abstract}

Kata Kunci : Ekowisata, Kuala Langsa, Pengetahuan masyarakat.

\begin{abstract}
This research goal is to gain a better understanding about the people knowledge upon mangrove ecotourism of Kuala Langsa. The descriptive - analytics methods are used in this research. The result gained in this activities had conclusion that whythe people ignorant about the ecotourism caused by the lack of education (elementary school), low level of socialization by the authorities, and the poverty around the neighborhood form the condition of the society unawareness about environmental issues in Kuala Langsa mangrove ecoturism site.
\end{abstract}

Keywords: Ecotourism, Kuala Langsa, People knowledge. 
Mahyuni Siska R, Pandia Ekariana S: Studi Pengetahuan Masyarakat Terhadap Konsep Ekowisata Hutan Bakau di Gampong Kuala Langsa

\section{PENDAHULUAN}

\section{Latar Belakang}

Tumbuhan bakau (Rhizophora sp.) banyak tersebar di wilayah pesisir laut yang beriklim tropis dan Indonesia memiliki jumlah hutan bakau terbesar di dunia (Kompasiana, 2018). Salah satu hutan bakau di Indonesia terdapat di Gampong Kuala Langsa Nanggroe Aceh Darussalam. Hutan mangrove (bakau) yang terletak di kelurahan (Gampong) Kuala Langsa, Kotamadya Langsa, propinsi Aceh merupakan kawasan ekowisata yang sekaligus menjadi kawasan konservasi. Gampong ini terbagi menjadi empat lingkungan yang mayoritas penduduknya bekerja sebagai nelayan dan pengrajin produk maritim. Hutan bakau merupakan tipe hutan yang vegetasinya tumbuh didaerah pasang surut yang tergenang ketika pasang dan bebas dari genangan air pada saat surut serta memiliki kelenjar salinitas pada daunnya (Mawardi \& Sarjani, 2017). Hutan Bakau yang masih asri secara alami terdapat di Gampong Kuala Langsa hingga sekarang. Hal tersebut tentunya menjadi fenomena yang sangat langka saat ini. Secara ekologi, hutan bakau kuala langsa memiliki keanekaragaman vegetasi bakau yang terdiri dari 5 suku dan 9 jenis yang didominasi spesies Rhizopora apiculata (Suwardi., dkk, 2017). Oleh karenanya pemerintah menetapkan kawasan tersebut sebagai wilayah konservasi. Seiring dengan langkah tersebut, pemerintah juga ingin agar masyarakat dapat terlibat langsung sehingga wilayah hutan bakau Kuala Langsa dibentuk menjadi kawasan ekowisata (Masriadi, 2019). Menurut (Muntasib, H. 2014), tujuan dari hal tersebut anatara lain diharapkan masyarakat sekitar dapat memperoleh manfaat ekonomi dari aktifitas ekowisata, dan juga mengedukasi masyarakat sekitar dan khalayak umum tentang ekowisata bakau sehingga mendukung konservasi Bakau di Kuala Langsa. Akan tetapi semangat tersebut kurang mendapat animo dari masyarakat sekitar. Hal inilah yang menjadi persoalan untuk diteliti ada apa sebenarnya dengan komunikasi dan sinergitas antara komponen masyarakat dengan stakeholder terkait. Tumbuhan bakau(Rhizophora sp.),memiliki banyak manfaat dalam ekosistem, disamping sebagai tempat bertelurnya ikan dan beberapa biota laut lainnya, juga sebagai tempat perlindungan anak-anak ikan dan biota laut lainnya, terutama yang baru menetas dan masih kecil. Selain itu,tumbuhan ini dapat memecah kekuatan ombak sehingga mencegah terjadiny aerosi (Kompasiana.com, 2018).

\section{Perumusan Masalah}

Perumusan masalah dalam penelitian ini antara lain adalah:

1. Mengetahui pengetahuan masyarakat Kuala Langsa tentang ekowisata.

2. Mengetahui tingkat pendidikan dan keadaan ekonomi masyarakat sekitar kawasan ekowisata Kuala Langsa.

\section{Tujuan Penelitian}

Adapun tujuan dari penelitian ini antara lain untuk melihat bentuk pemahaman masyarakat tentang konsep ekowisata. Hal tersebut tentunya akan sangat dipengaruhi oleh tingkat pendidikan dan keadaan ekonomi yang dihadapi masyarakat sekitar kawasan ekowisata Kuala Langsa.

\section{Manfaat Penelitian}

Tujuan dari hal tersebut anatara lain diharapkan masyarakat sekitar dapat memperoleh manfaat ekonomi dari aktifitas ekowisata, dan juga mengedukasi masyarakat sekitar dan khalayak umum tentang ekowisata bakau sehingga mendukung konservasi Bakau di Kuala Langsa. 
Mahyuni Siska R, Pandia Ekariana S: Studi Pengetahuan Masyarakat Terhadap Konsep Ekowisata Hutan Bakau di Gampong Kuala Langsa

\section{METODE PENELITIAN}

Penelitian ini menggunakan metode deskriptif random sampling dengan wawancara dan menggunakan angket.

\section{Populasi dan Sampel Penelitian}

Populasi yang digunakan dalam penelitian ini ialah seluruh masyarakat Kuala Langsa yang terbagi menjadi empat lingkungan.

\section{Teknik Pengumpulan Data}

Data diambil dari 100 responden yang terbagi dari empat lingkungan (25orang/ lingkungan) dan diambil tersebar acak (Arikunto, 2010). Data yang dikumpulkan anatara lain adalah hasil wawancara dan kuesioner sedangkan instrumen penelitian adalah berupa angket pengetahuan konsep ekowisata bagi masyarakat Kuala Langsa.

\section{Teknik Analisa Data}

Untuk mendapatkan hasil dari kegiatan pengumpulan data diatas maka tim akan mentabulasi data sebagai berikut: (1) reduksi data; (2) penyajian data; (3) penyimpulan; (4) verifikasi data.

\section{HASIL DAN PEMBAHASAN}

Hasil yang diperoleh dari penelitian ini adalah sebagai berikut:

\section{Hasil Penelitian}

Hasil yang didapat dari hasil wawancara menunjukan sebesar $35 \%$ penduduk kuala langsa berpendidikan SD, 27\% SMP, 33\% SMA, dan 5\% Lulusan Perguruan Tinggi. Sebagian besar masyarakat memiliki kegiatan ekonomi sebagai nelayan 35\% dan $44 \%$ sebagai ibu rumah tangga yang mempunyai kegiatan sampingan mengupas tirom (tiram). Hanya sebesar $5 \%$ dari yang berwirausaha dari total seluruh responden. Penyebaran angket bertujuan untuk melihat beberapa indikator tentang pengetahuan ekowisata diantaranya; 1). Pengetahuan tentang ekowisata; 2). keterlibatan masyarakat pada kawasan ekowisata; 3). Edukasi dan komunikasi kepada masyarakat.Hasil dari penyebaran angket survei dapat dilihat pada gambart-gambar dibawah ini:

\section{Wisata hutan mangrove sebagai kawasan Ekowisata}

\section{Gambar 1. Pengetahuan masyarakat tentang hutan mangrove sebagai objek ekowisata}

Pada gamabar 1. Menampilkan data apakah masyarakat mengetahui kawasan wisata hutan bakau kuala langsa sebagai kawasan ekowisata 
Mahyuni Siska R, Pandia Ekariana S: Studi Pengetahuan Masyarakat Terhadap Konsep Ekowisata Hutan Bakau di Gampong Kuala Langsa

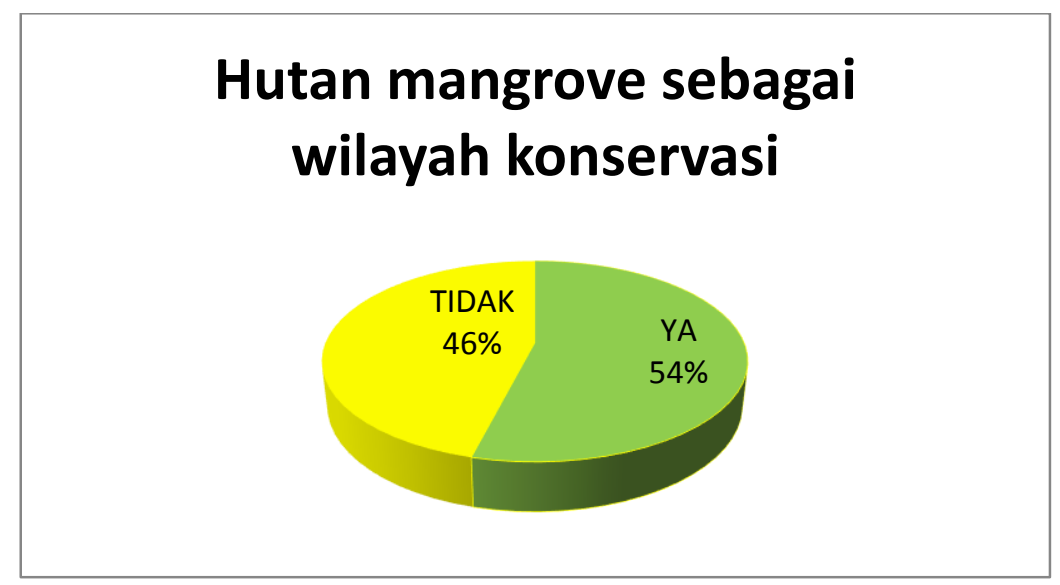

Gambar 2. Pengetahuan masyarakat tentang hutan mangrove sebagai wilayah konservasi.

Pada gamabar 2. Menampilkan data apakah masyarakat mengetahui kawasan wisata hutan bakau kuala langsa sebagai wilayah konservasi

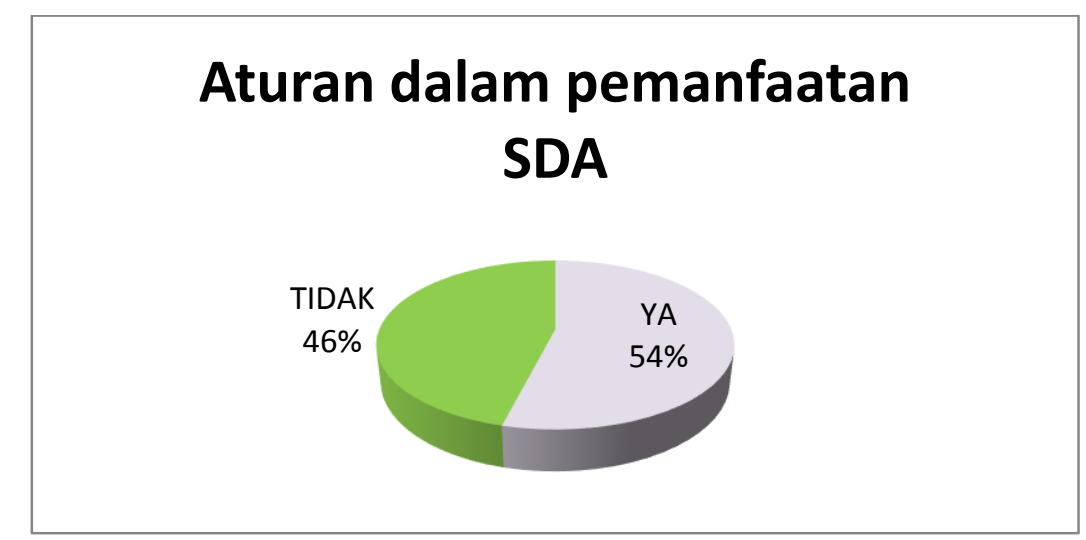

Gambar 3. Pengetahuan masyarakat tentang aturan pemanfaatan dan pengelolaan sumber daya alam hutan mangrove

Pada gamabar 3. Menampilkan data apakah masyarakat mengetahui adanya aturan dalam pemanfaatan dan pengelolaan sumber daya hutan mangrove

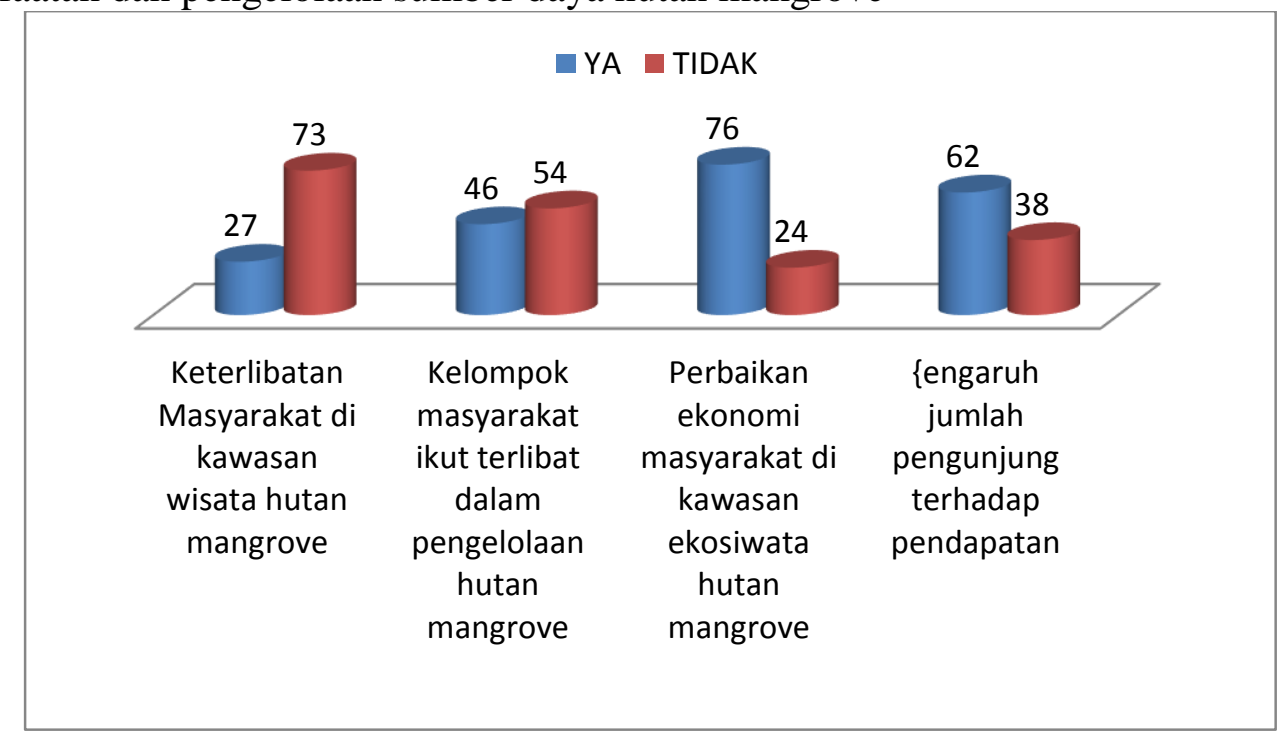

Gambar 4. Keterlibatan masyartakat pada kawasan ekowisata 
Mahyuni Siska R, Pandia Ekariana S: Studi Pengetahuan Masyarakat Terhadap Konsep Ekowisata Hutan Bakau di Gampong Kuala Langsa

Pada gamabar 4. Menampilkan data keterlibatan masyarakat dalam hubungan ekonomi dengan pengelolaan hutan mangrove sebagai kawasan ekowisata

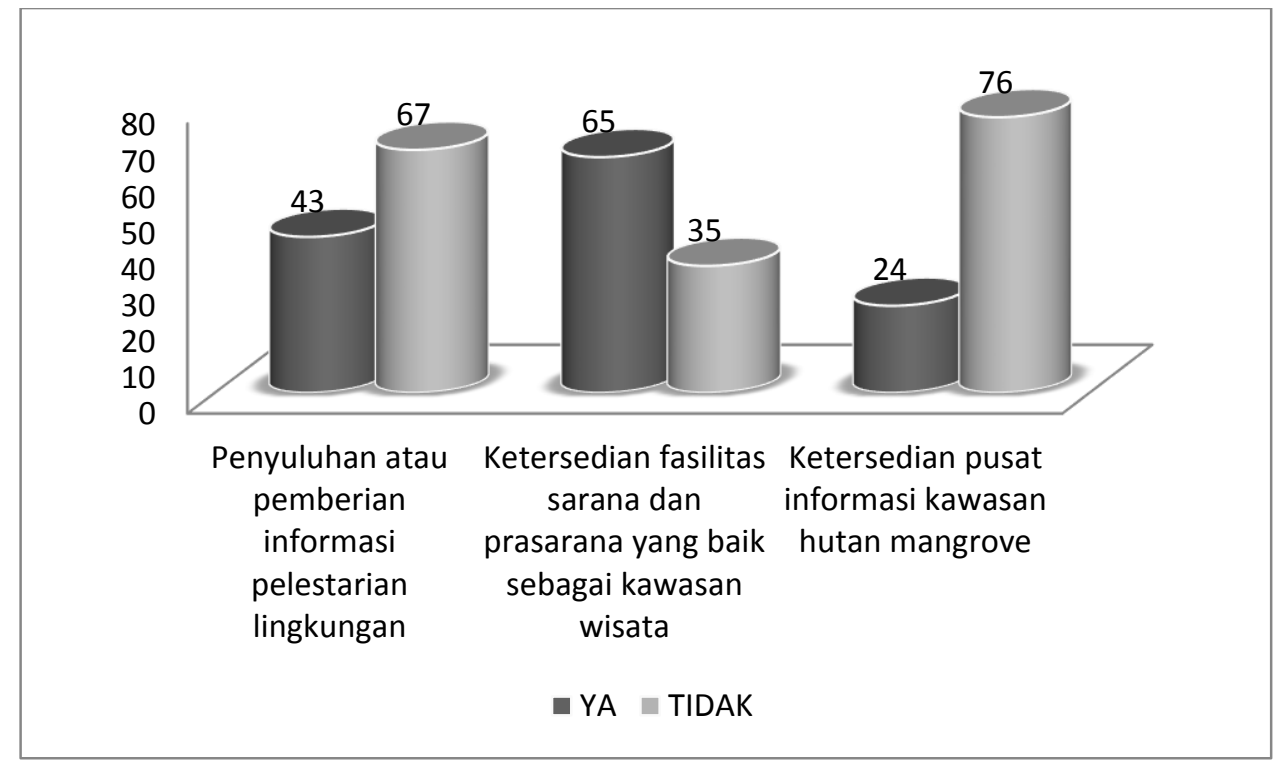

\section{Gambar 5. Edukasi kepada masyarakat}

Pada gamabar 5. Menampilkan data pola komunikasi antara masyarakat sekitar dengan pengelolaan sarana dan prasaran di kawasan ekowisata.

\section{Pembahasan}

Dari hasil penelitian diperoleh data secara umum bahwa hampir sebagian besar masyarakat sekitar Kuala Langsa belum mengetahui informasi memadai tentang ekowisata. Hal tersebut ditunjukkan oleh grafik pada gambar 1 diatas, sesuai dengan penelitian yang telah dilakukan oleh (Hidayati, J, 2016). Hal tersebut disebabkan oleh berbagai faktor, seperti kurangnya sosialisasi dari pemerintah, baik dalam bentuk penyuluhan, event-event yang melibatkan masyarakat langsung dalam kampanye ekowisata, maupun kegiatan lain yang berkaitan dengan ekowisata. Keadaan ekonomi masyarakat sekitar juga turut mempengarungi tingkat kepedulian masyarakat terhadap kawasan ekowisata. Ketika kegiatan ekowisata kurang ramai dan masyarakat dituntut untuk tetap harus memenuhi kebutuhan kesehariannya, masyarakat akan lebih memilih untuk melakukan pekerjaan lain yg lebih pasti aliran dananya seperti menangkap ikan dan menjadi pengrajin produk maritim seperti pengupas tiram. Hal inilah yang turut menjadi penyebab kurang pekanya masyarakat terhadap isu-isu seputar pengembangan potensi kawasan ekowisata Kuala Langsa, termasuk isu-isu lingkungan seperti pentingnya menjaga kebersihan dan keasrian lingkungan di sekitar kawasan. Ketidak pekaan terhadap kondisi lingkungan sekitar tersebut kian lama berkembang menjadi ketidak pedulian masyarakat. Hal ini dapat dibuktikan dengan banyaknya sampah rumah tangga sekitar yang langsung dibuang kelaut. Beberapa masyarakat juga memanfaatkan secara langsung kayu bakau untuk bahan kebutuhan papan. Hal tersebut tentunya diatur dalam undang-undang konservasi sumber daya alam. Namun sekali lagi ketidak pedulian masyarakat sekitar juga dipengaruhi oleh pengetahuan dan pemahamannnya terhadap kawasan ekowisata sebagai wilayah konservasi seperti yang ditunjukkan pada gambar 2 dan gambar 3. Pengetahuan masyarakat terkait komunikasi dan sinergitas dengan pihak-pihak terkait guna mngembangkan dan memaksimalkan potensi kawasan ekowisata dipengaruhi oleh pola komunikasi dan arus kegiatan disekitar kawasan ekowisata. Seperti yang ditunjukkan oleh gambar 4, bahwasanya banyak masyarakat yang belum dilibatkan terutama 
Mahyuni Siska R, Pandia Ekariana S: Studi Pengetahuan Masyarakat Terhadap Konsep Ekowisata Hutan Bakau di Gampong Kuala Langsa

secara langsung dalam kegiatan-kegiatan yang dlakukan oleh stakeholder terkait di seputar kawasan. Padahal data menunjukkan bahwa semenjak ditetapkannya Kuala Langsa sebagai kawasan ekowisata, masyarakat mendapatkan dampak positif terutama dalam peningkatan ekonomi. Hal tersebut juga dipengaruhi oleh jumlah pengunjung yang datang ke kawasan tersebut. Oleh karena itu, perlu dilakukan pola komunikasi yang lebih efektif dan sinergis antara masyarakat Kuala Langsa dengan pihak-pihak terkait agar semakin banyak masyarakat sekitar yang dapat terlibat langsung dalam pengembangan kawasan ekowisata Kuala Langsa. Optimasi sarana dan prasarana termasuk pusat informasi pariwisata juga berperan sangat penting untuk memperkenalkan dan mengedukasi masyarakat secara luas tentang ekowisata hutan mangrove (gambar 5).

\section{KESIMPULAN}

Kesimpulan dari penelitian antara lain adalah:

1. Hampir sebagian besar masyarakat Kuala Langsa belum memahami arti ekowisata.

2. Hampir sebgaian besar masyarakat Kuala Langsa belum mengetahui tentang kawasan ekowisata juga menjadi bagian dari wilayah konservasi bakau.

3. Hampir sebagian besar masyarakat Kuala Langsa belum memahami aturan terkait pengelolaan dan pemanfaatan SDA di wilayah konservasi bakau Kuala Langsa.

4. Kurang dilibatkannya masyarakat sekitar kawasan Kuala Langsa baik langsung ataupun tidak langsung dalam pengelolaan kawasan ekowisata, dimana pengelolaan kawasan tersebut memberikan dampak peningkatan ekonomi bagi masyarakat sekitar secara langsung sehingga menimbulkan sikap ketidakpedulian masyarakat sekitar terhadap kawasan ekowisata Kuala Langsa.

5. Diperlukan upaya-upaya kreatif melalui pola komunikasi yang efektif dan sinergis antara seluruh pihak yang terkait untuk mengembangkan secara optimal kawasan konservasi ekowisata Kuala Langsa terutama ditengah masa pandemi Covid-19 sekarang ini.

\section{DAFTAR PUSTAKA}

Arikunto, Suharsimi. 2010. Prosedur Penelitian Suatu pendekatan Praktek. Rineka Cipta:Jakarta.

Hidayati, Juli. 2016. Analisis Potensi Sumberdaya Ekosistem Mangrove Untuk Pengembangan Ekowisata di Desa Kuala Langsa Kecamatan Langsa Barat. Skripsi: UniversitasNegeri Medan.

https://www.kompasiana.com/luluulfirdausiah/5c15065112ae940dd72d49a8/rhizophorasp-si-pemecah-gelombang. diakses pada tanggal 20 agustus 2020.

Masriadi. 2019. Kota Langsa Kembangkan Ekowisata Hutan Mangrove.

https://www.kompasiana.com/nia agustin/5c6aa0e512ae945fae63ac b2/relevansipendidikan-karakter-bagi-orang-dewasa?page=all. diakses pada tanggal 13 Agustus 2019.

Mawardi \& Sarjani, Tri Mustika. 2017 Pengelolaan Alam dan Pesisir. Prodi Pendidikan Biologi Universitas Samudra: Langsa.

Muntasib, Harini. 2014. Rekreasi Alam dan Ekowisata. IPB Press: Bogor.

Suwardi, AB \& Zidni IA, \& Sofiyan. 2017. Komposisi Jenis Dan Cadangan Karbon Tersimpan Di Hutan Mangrove Kuala Langsa, Aceh. SEMNAS BIOETI KE-4 \& KONGRES PTTI KE-12: Padang.

\begin{tabular}{|l|l|l|l|}
\hline Accepted Date & Revised Date & Decided Date & Accepted to Publish \\
\hline 19 Agustus 2020 & 20 Agustus 2020 & 23 Agustus 2020 & Ya \\
\hline
\end{tabular}

